\title{
Minorities in leadership: are we moving the needle?
}

\author{
Aurora D. Pryor ${ }^{1} \cdot$ Amanda Bader $^{1} \cdot$ Mark Talamini $^{1}$
}

Received: 16 September 2019 / Accepted: 16 September 2019 / Published online: 31 October 2019

(c) Springer Science+Business Media, LLC, part of Springer Nature 2019

Underrepresentation of minority groups in the medical field has garnered increased interest in recent years. Lack of diversity in medicine is a pressing issue as it impacts many areas of medicine. A definition of diversity is "the composition of differing elements" [1]. When used to describe a population, however, the term is multifaceted. It does not just refer to different genders, races and ethnicities; it also includes those of different religions, socioeconomic status, sexual orientation, mental/physical abilities, and education levels. As the United States population grows more diverse, so must its medical professional workforce. But we are not yet there; the current US physician workforce does not reflect the diversity of our contemporary society.

Underrepresented minorities have improved compliance, higher satisfaction, and greater participation in clinical trials when their provider is also an underrepresented minority $[2,3]$. Physician diversity combats disparities in healthcare delivery, as physicians of color are more likely to work in underserved communities and treat poor payor mix patients $[4,5]$. Provider diversity also promotes innovation and creativity by enhancing collective intelligence. Heterogeneous groups with different genders, ages, ethnicities, ages, experiences, and cultures pool multiple perspectives in response to new problems $[6,7]$. What should diversity in surgery look like today? How diverse should the leadership of surgical societies be? Specifically, what is the current state of diversity among SAGES leadership?

To address these questions, we surveyed gender and race information from significant surgical organizations (Dr. Jo Buyske for the American Board of Surgery, Dr. Patricia Turner for the American College of Surgeons and Ms. Sallie Matthews for SAGES). In addition, we examined race and gender among medical school applicants at Stony Brook University Renaissance School of Medicine Medical office

Mark Talamini

mark.talamini@stonybrookmedicine.edu

1 Department of Surgery, Stony Brook University Renaissance School of Medicine, Stony Brook, NY 11794-8191, USA of admission. Data regarding residents and faculty at Stony Brook was also collected.

A shift in the status quo is beginning to emerge. Prior to 2009 the executives at the American Board of Surgery were all Caucasian males. Now three are women and two are men, all Caucasian. There have been two African American chairs and three female chairs of the ABS. The current board of directors consists of 23 white men, 9 white women, 3 men of Middle Eastern descent, 3 men of Asian descent, and 1 woman of Asian descent. The newly elected directors include two white men, two Asian men, one African American man, and three white women. In terms of component ABS boards, pediatric surgery has seated its first female minority chair while vascular surgery has its first female chair. Trauma/critical care has had one female chair and surgical oncology has had one African American chair. There has been one minority exam committee chair; all other leaders have been white males.

The American College of Surgeons (ACS) Board of Governors leadership has been all white men except one African American male vice-chair and one white female president. The Board of Regents has had one African American chair. There have been three non-white presidents of ACS.

SAGES leadership has seen a shift in representation towards more minorities and more women over time (Fig. 1). Figure 2 depicts the gender and race profile for the current SAGES Board of Governors.

The US population is increasingly diverse as seen in Fig. 3, with $50.8 \%$ male and $49.2 \%$ female. When we compare this to the Stony Brook Department of Surgery faculty, there is a relative difference in representation (Fig. 4). Yet the Stony Brook surgical residents and medical students are more diverse than the population in general (Figs. 5, 6). Interestingly, looking at the national pool of medical school applicants for 2017, it mimics the diversity we see in the US population (Fig. 7). At the collegiate level, diversity is increasing; 50.8\% of accepted Harvard freshman in 2017 were from minority groups including African Americans, Hispanics, Asian Americans, Native Americans and Native Hawaiians, greater than the $47.3 \%$ of the previous year [8]. 
Fig. 1 SAGES leadership from 1987 to 2018. Each row represents a surgeon and their time on the board by year. The black outlines represent the presidents

Fig. 2 SAGES Board of Governors representation by gender and race
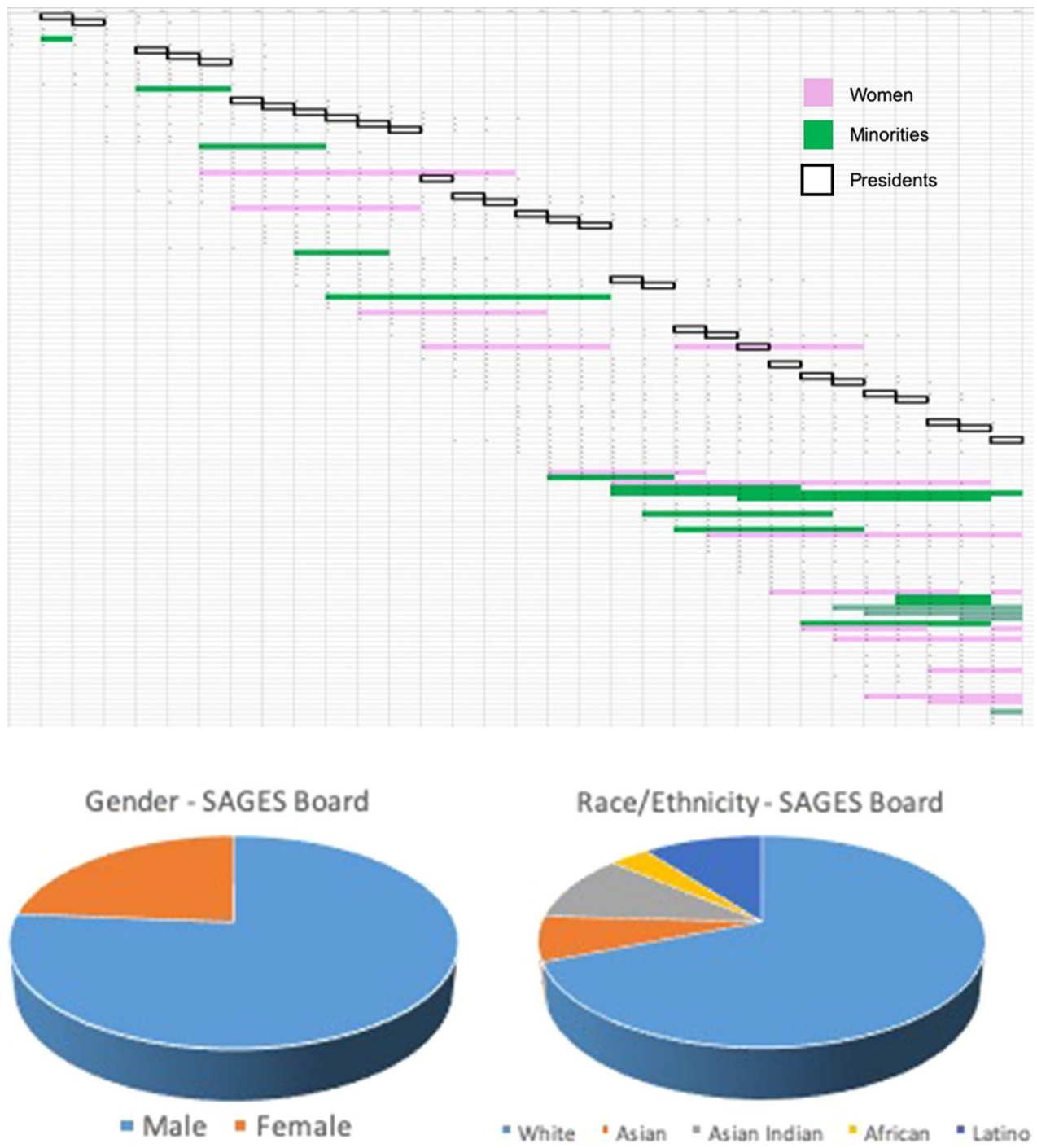

Gender - US Population (2010)

Race/Ethnicity - US Population (2010)
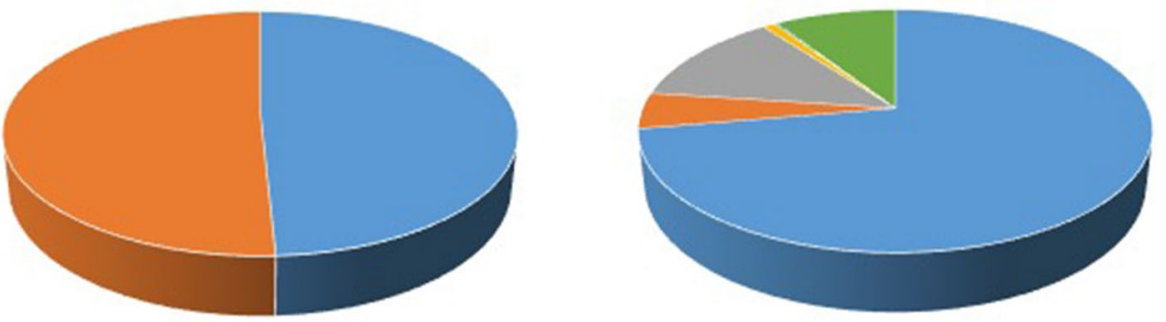

Fig. 3 US population repreaccording to 2010 statistics
The benefit of diversity and heterogeneity among provider teams in medicine depends primarily on the power of collective intelligence, defined as the ability of the group to outperform the individual in decision making. Enhanced group performance through collective wisdom, a social psychology principle, is woven into the current thinking and practice in business, economics, and politics. It is less assumed and adopted in medicine. One study examining the potential effect of collective intelligence in emergency medicine found that combining the independent decisions of medical students from different classes increased diagnostic accuracy and treatment adequacy [9].

While the degree of diversity in surgical departments and surgical leadership is improving, there is much more 
Fig. 4 Institution's surgery faculty representation by gender and race

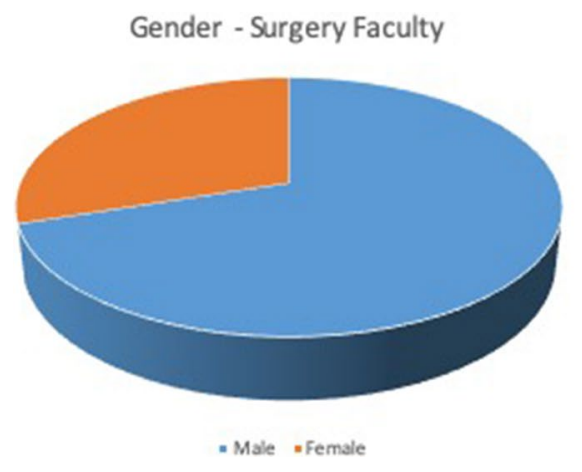

Fig. 5 Institution's surgical resident representation by gender and race

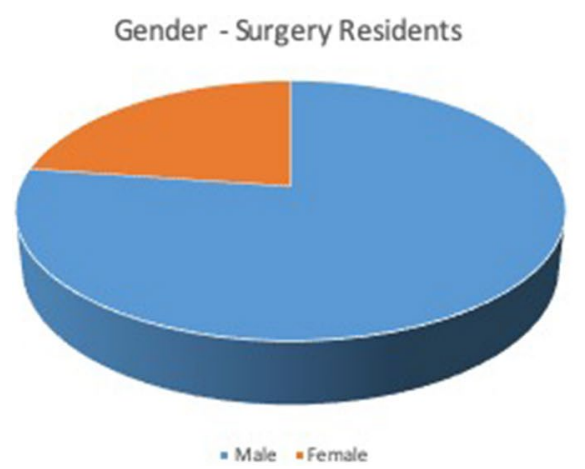

Gender - Medical Students

student representation by gender and race

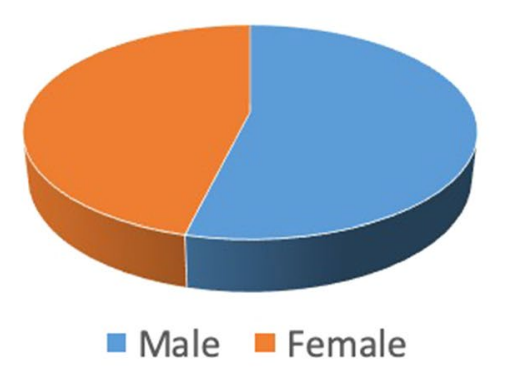

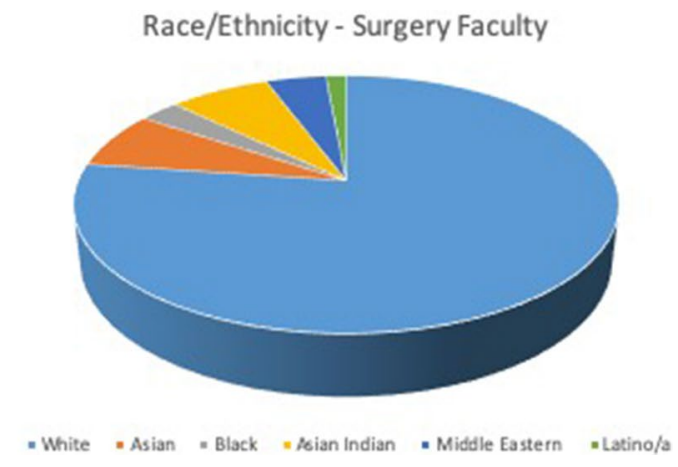

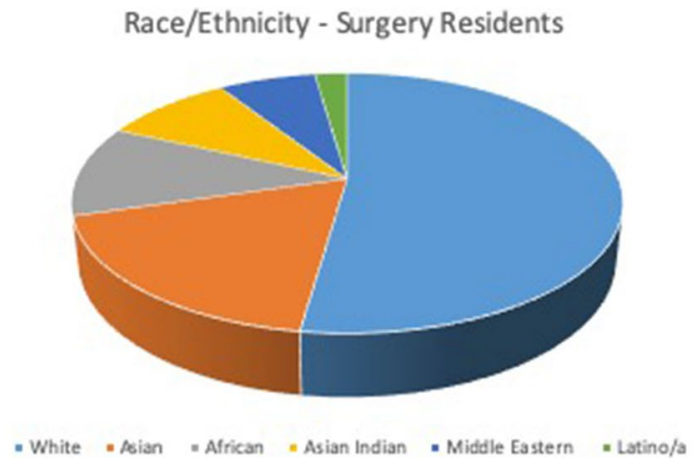

Race/Ethnicity - Surgery Residents

Race/Ethnicity - Medical Students

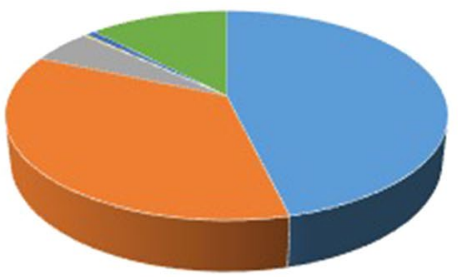
- White
Asian / Indian
african
- Native American
- Latino/a
- Other

Fig. 7 National medical school applicant pool representation by gender and race

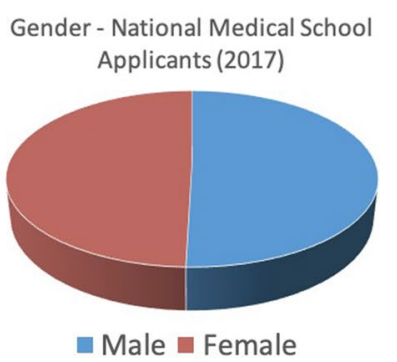

Race/Ethnicity - National Medical School Applicants (2017)

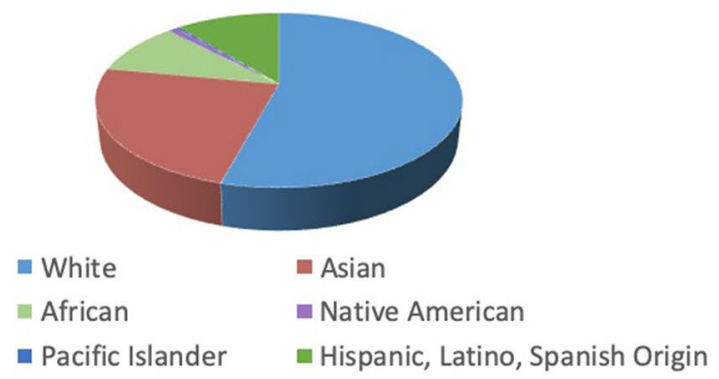

to be accomplished. The proportion of assistant professors that are Black or Hispanic in academic surgery remained unchanged or decreased over the last 10 years with a similar trend among associate professors, full professors and tenured surgeons. While the Black and Hispanic US 
populations are increasing, Black and Hispanic medical school graduates are decreasing [10].

The differences in mix between surgery residents and the overall physician resident workforce may in part be causing the ongoing diversity deficit in the field of surgery [11]. Andriole et al. write that despite the overall increase in the number of women and African Americans in the ACGME-resident workforce, the proportion of these two groups in most core surgery specialty residencies is markedly lower than that of males and other races and ethnicities. The authors argue that applicant specialty preferences, resident selection processes, and resident attrition, are all factors. Yet these trends are not seen in obstetrics and gynecology. We propose that the presence of more same-gender or same-race role models may account for the difference in $\mathrm{Ob} / \mathrm{Gyn}$.

Action is beginning with regard to diversity in surgical leadership. Dr. Caprice Greenberg's presidential address at the Academic Surgical Congress Meeting in 2017 titled "Sticky Floors and Glass Ceilings" focused on the impact of implicit bias, gender schemas and gender roles upon women in surgery, and the barriers women surgeons face climbing the leadership ladder [12]. Dr. Keith Lillemoe expanded on these points in his address as Academic Surgical Association president in 2017. He discussed the recruitment of female surgical leaders, mentorship of female surgical residents and faculty, and appropriate compensation for female faculty [13]. In an effort to combat this lack of diversity in surgical leadership, many surgical societies have begun to set up task forces specifically aimed at understanding and addressing inequities in surgery.

In 2006, several minimally invasive surgeons established the Diverse Surgeon's Initiative (DSI) to address diversity in the minimally invasive surgery (MIS) community. This program provided URMs in surgery with an opportunity to interact and work with MIS fellowship directors in an intimate environment, giving members of the program better opportunities for fellowship matching. Using the DSI, Butler et al. found that $86 \%$ of DSI graduates went on to match into a fellowship, compared with the $77 \%$ overall match rate of PGY-5 surgical residents [14].

The Association of American Medical Colleges (AAMC) is also addressing diversity at the medical student level. For example, the Medical Minority Applicant Registry (MedMAR) allows medical school applicants from groups historically underrepresented in medicine or those who are economically disadvantaged to apply to schools through Med-MAR. The AAMC also has a number of effective "academic enrichment" summer programs for college students from underrepresented racial and ethnic groups in the health professions [15]. At the undergraduate college level, many universities have developed programs that create opportunities for more women to be involved in science and engineering. For example, Stony Brook University has a program named Women in Science and Engineering (WISE) that not only provides college scholarships for those in the program but also gives these women opportunities on and off campus to attend events and programs designed specifically for them [16].

Within SAGES, the "We Are SAGES (WRS)" initiative was created as a means to address "challenges in race, gender, inclusion, and equity." [17]. WRS administered a survey to the SAGES members, polling them on overall SAGES experiences, resources, opportunities, mentorship, attitude, and experiences. The survey (with a $52.1 \%$ response rate) reported a largely positive experiences in SAGES, although some voiced concerns with regard to minorities in leadership roles or representation of speakers at meetings [17]. Only $6.4 \%$ reported overt discrimination within the organization based on gender, race/ethnicity, or sexual orientation. WRS proposed solutions such as mandated training in unconscious bias, recurring sessions on diversity at SAGES annual meetings, and creating collaboration with other organizations such as Society of Black Academic Surgeons and Association of Women Surgeons. SAGES is internally making major efforts to enhance female and minority representation at all leadership levels and within the annual meeting.

While medicine is not the only professional field dealing with issues of diversity and representation, society and medical professionals may have the most to lose if we do not achieve meaningful change. This is a problem that reaches far beyond medicine itself; it affects population at large. SAGES, to its credit, is intentionally driving positive change to breakdown the gender and racial barriers in medicine.

Acknowledgments We would like to acknowledge and thank Dr. Jo Buyske, Dr. Patricia Turner, and Ms. Sallie Matthews. We would also like to thank Stony Brook University Renaissance School of Medicine's Office of Admissions.

\section{References}

1. Diversity (2018) merriam-webster.com. Accessed 8 May 2018

2. Branson RD, Davis K, Butler KL (2007) African Americans' participation in clinical research: importance, barriers, and solutions. Am J Surg 193(1):32-39

3. Hughes TB, Varma VR, Pettigrew C, Albert MS (2017) African Americans and clinical research: Evidence concerning barriers and facilitators to participation and recruitment recommendations. Gerontologist 57(2):348-358

4. Marrast LM, Zallman L, Woolhandler S, Bor DH, McCormick D (2014) Minority physicians' role in the care of underserved patients: diversifying the physician workforce may be key in addressing health disparities. JAMA Int Med 174(2):289-291 
5. Xu G, Fields SK, Laine C, Veloski JJ, Barzansky B, Martini CJ (1997) The relationship between the race/ethnicity of generalist physicians and their care for underserved populations. Am J Public Health 87(5):817-822

6. Lightfoote JB, Fielding JR, Deville C, Gunderman RB, Morgan GN, Pandharipande PV, Duerinckx AJ, Wynn RB, Macura KJ (2014) Improving diversity, inclusion, and representation in radiology and radiation oncology part 1: why these matter. JACR 11(7):673-680

7. Page SE (2008) Diverse perspectives (The difference: how the power of diversity creates better groups, firms, schools, and societies). Princeton University Press, Princeton

8. Fernandes D (2017) The majority of Harvard's incoming class is nonwhite. https://www.bostonglobe.com/metro/2017/08/02. Accessed 1 June 2018

9. Kämmer JE, Hautz WE, Herzog SM, Kunina-Habenicht O, Kurvers RH (2017) The potential of collective intelligence in emergency medicine: pooling medical students' independent decisions improves diagnostic performance. Med Decis Making 37(6):715-724

10. Abelson JS, Symer MM, Yeo HL, Butler PD, Dolan PT, Moo TA, Watkins AC (2017) Surgical time out: our counts are still short on racial diversity in academic surgery. Am J Surg 215(4):542-548

11. Andriole DA, Jeffe DB, Schechtman KB (2007) Is surgical workforce diversity increasing? J Am Coll Surg 204(3):469-477
12. Academic Surgical Congress (2017, February 21) AAS presidential address. [Video File]. https://www.youtube.com/watch $? \mathrm{v}=\mathrm{KHo} 1 \mathrm{x} 2 \mathrm{sk} 0 \mathrm{gw}$

13. American Surgical Association (2017, December 6) 2017 ASA presidential address. [Video File]. https://www.youtube.com/ watch? $\mathrm{v}=1 \mathrm{DiYB} 1 \mathrm{sIqpg}$

14. Butler PD, Britt LD, Green ML, Longaker MT, Geis WP, Franklin ME, Ruhalter A, Fullum TM (2010) The diverse surgeons initiative: an effective method for increasing the number of underrepresented minorities in academic surgery. J Am Coll Surg 211(4):561-566

15. Minorities in Medicine. https://students-residents.aamc.org/choos ing-medical-career/medical-careers/deciding-if-medicine-you/ minorities-medicine/. Accessed 1 June 2018

16. Women in Science and Engineering (WISE) http://www.wise. sunysb.edu/aboutus.shtml. Accessed 1 June 2018

17. Telem DA, Qureshi A, Edwards M, Jones DB, Force WT (2018) SAGES climate survey: results and strategic planning for our future. Surg Endosc 32(10):4105-4110

Publisher's Note Springer Nature remains neutral with regard to jurisdictional claims in published maps and institutional affiliations. 